\title{
Defining characteristics of educational competencies
}

\author{
Mark A Albanese ${ }^{1}$, George Mejicano ${ }^{2}$, Patricia Mullan ${ }^{3}$, Patricia Kokotailo ${ }^{4} \&$ Larry Gruppen $^{3}$
}

CONTEXT Doctor competencies have become an increasing focus of medical education at all levels. However, confusion exists regarding what constitutes a competency versus a goal, objective or outcome.

OBJECTIVES This article attempts to identify the characteristics that define a competency and proposes criteria that can be applied to distinguish between competencies, goals, objectives and outcomes.

METHODS We provide a brief overview of the history of competencies and compare competencies identified by international medical education organisations (CanMEDS 2005, Institute for International Medical Education, Dundee Outcome Model, Accreditation Council for Graduate Medical Education/American Board of Medical Specialties). Based upon this review and comparisons, as well as on definitions of competencies from the literature and theoretical and conceptual analyses of the underpinnings of competencies, the authors develop criteria that can serve to distinguish competencies from goals, objectives and outcomes.

RESULTS We propose 5 criteria which can be used to define a competency: it focuses on the performance of the end-product or goal-state of instruction; it reflects expectations that are external to the immediate instructional programme; it is expressible in terms of measurable behaviour; it uses a standard for judging competence that is not

\footnotetext{
${ }^{1}$ Population Health Sciences, School of Medicine and Public Health, University of Wisconsin, Madison, Wisconsin, USA

${ }^{2}$ Internal Medicine and Office of Continuing and Professional Development, School of Medicine and Public Health, University of Wisconsin, Madison, Wisconsin, USA.

${ }^{3}$ Department of Medical Education, University of Michigan Medical School, Ann Arbor, Michigan, USA.

${ }^{4}$ Department of Pediatrics, School of Medicine and Public Health, University of Wisconsin, Madison, Wisconsin, USA
}

Correspondence: Mark A Albanese, 610 Walnut Street, 1007C WARF, Madison, Wisconsin 53726-2397, USA. Tel: 001608263 4714;

Fax: 001608263 2820; E-mail: maalbane@wisc.edu dependent upon the performance of other learners, and it informs learners, as well as other stakeholders, about what is expected of them.

CONCLUSIONS Competency-based medical education is likely to be here for the foreseeable future. Whether or not these 5 criteria, or some variation of them, become the ultimate defining criteria for what constitutes a competency, they represent an essential step towards clearing the confusion that reigns.

KEYWORDS *education, medical; clinical competence/ *standards; *health knowledge, attitudes, practice; goals.

Medical Education 2008: 42: 248-255

doi:10.1111/j.1365-2923.2007.02996.x

\section{INTRODUCTION}

Doctor competencies have become an increasing focus of medical education at all levels across the globe. Despite widespread adoption of competencies, there is still confusion about what constitutes a competency: is it simply another name for an objective, goal or outcome? Or is it a distinct and separate entity? In this article, we provide a brief overview of the historical development of competencies, show various definitions of existing competencies and compare competencies developed internationally. We identify 5 criteria for defining a competency. We use the proposed criteria to evaluate several competencies as a means of assessing the viability of the 5 criteria. Finally, we provide examples of what are and are not competencies.

\section{A BRIEF HISTORY OF COMPETENCIES}

The premise that explicit minimal competencybased education would promote accountability received considerable attention in the $1970 \mathrm{~s}^{1}$ Carraccio et al. ${ }^{2}$ traced the rise and demise and rise again of the competency movement in medical 


\section{Overview}

\section{What is already known on this subject}

Competencies are being widely adopted as a framework for doctor education, certification and maintenance of certification. Confusion remains about what constitutes a competency.

\section{What this study adds}

We propose 5 criteria for defining what constitute educational competencies and contrast these with criteria for objectives, goals and outcomes.

\section{Suggestions for further research}

Are the 5 criteria sufficient or is further refinement necessary?

education through a literature review spanning 1966-2001. We begin our history with the second coming of competencies in the early 1990s, referring the reader to Carraccio et al. ${ }^{2}$ for the earlier treatments.

In 1990, competency-based education rose from the ashes when the Society for the Teaching of Family Medicine (STFM) published a new competency-based curriculum proposal entitled 'Essentials for Family Practice'. The Royal College of Physicians and Surgeons of Canada began the CanMEDS 2005 Project in 1993 to identify societal health care needs and, based on these, define a profile of competencies essential to practising specialist doctors in Canada. ${ }^{4}$ One of the most relevant developments for undergraduate medical education (UME) was the initiation of the Medical School Objectives Project (MSOP) by the Association of American Medical Colleges (AAMC) in 1996. A report on the MSOP was published in 1999,5 'priming the pump' for educators to think about what we should expect medical students to be able to do, no matter which medical school they attend.

The year 1999 proved to be pivotal in the evolution of the competency movement. The defining moment for the emergence of competencies in the USA occurred when the Accreditation Council for Graduate Medical Education (ACGME) and the American Board of Medical Specialties (ABMS) jointly agreed on 6 competencies for the certification and mainte- nance of certification of doctors. ${ }^{6}$ Despite the lack of a compelling mandate to actually implement competencies, the ACGME began holding residency programmes accountable for implementing competency-based approaches, although the adequacy of assessment tools to evaluate these competencies remained uncertain. ${ }^{7,8}$

Also in 1999, Harden et al. ${ }^{9,10}$ published a 5-part guide to outcome-based education identified as the Dundee Outcome Model (DOM). This guide drew upon Gardner's theory of multiple intelligences ${ }^{11}$ and a 3-level model based upon an analysis of the work of a doctor to support the importance and value of linking education to the longterm behaviour desired from learners. Competency-based and outcome-based medical education focus on the result of the educational process, not the process itself. Thus, although they are not necessarily equivalent, they share a similar focus.

\section{WHAT IS A COMPETENCY?}

\section{International examples of competencies}

Six competencies were developed by the ACGME/ABMS, 7 by the CanMEDS 2005 Project, ${ }^{4} 7$ by the Institute for International Medical Education (IIME) (referred to as the 'Global Minimum Essential Requirements') and 12 by the DOM (referred to as the 'Learning Outcomes for a Competent and Reflective Practitioner'). (See Appendices S1 and S2 [supplementary material]).

Our attempt to group them by similarity was only marginally successful as they use different descriptors and different methods of grouping. It also seemed that some of the competencies were split between different categories in the different sets. The cleanest matching across the different sources occurred for the first 2 competencies: 'Professionalism' and 'Communication skills'. After that, the alignment becomes less clear as the terms used are not as directly comparable.

Although the literature provides several lists of competencies, the definitions of what exactly constitutes a competency tend to be imprecise and non-specific.

A problem that may be exemplified by our use of the ABMS/ACGME competencies for our base comparison is the potential contextual influence on competencies. In the USA, the health care system is generally a for-profit operation, which is a relatively unique approach in global terms. The ABMS/ ACGME competencies use some terminology that 
suggests they evolved from business. The terms 'system-based' and 'practice-based' tend to have a business-oriented tone to them. However, it can also be argued that they are represent a recognition that the practice of medicine is heavily dependent on the context of practice - which makes them sociological rather than business-based concepts. Among the competencies we have seen, these terms are unique to the USA. What is uncertain is whether the fact that the competencies are derived from either business or sociology contexts makes any difference when they are put into practice. If doctors are held to exactly the same standards of performance in their interactions with patients despite differences in the phrasing of the general competencies, then the differences represent simple semantics. However, if even minor differences in wording lead to different behavioural measures at the level of doctor-patient interaction, then the broader competencies must be worded with great care.

\section{Definitions of competencies}

Four examples of definitions of a competent doctor drawn from the health education literature are given below; the fifth definition is our own.

1 Residents 'are able to provide medical care and/or other professional services in accord with practice standards established by members of the profession and in ways that conform to the expectations of society.' 12

2 Competencies are 'a complex set of behaviours built on the components of knowledge, skills, attitudes and "competence"' as personal ability'.2

3 Competencies represent a 'set of skills, knowledge and attitudes necessary for the broad practice of public health'. 13

4 Competencies are 'important observable knowledge, skills and attitudes'.

5 Competencies are 'knowledge, skills, attitudes and personal qualities essential to the practice of medicine'. ${ }^{14}$

Although many consider what constitutes a competency to be universally understood, there is substantial variability in the definitions that have been used. Neufeld (1985) states: 'Ask any number of clinical educators or professional groups to define the term clinical competence and somewhat different responses will be obtained from each of them. ${ }^{, 15}$ (p 3) McGaghie et al., are even more pessimistic in their assessment of whether general competencies can be determined: '...the definition of medical competence is bound to local political, social, and economic circumstances, to health needs, to the availability of resources, and to the structure of the health care system. Thus any effort to find a universal definition of competence will inevitably fail. ${ }^{, 16}$ (p 23) This scepticism over the viability of general competencies, however, has not stopped individuals and professional organisations from producing literally thousands of competencies.

What makes matters even more confusing is that it is difficult to separate a competency from what have been called goals and objectives. Thorndike and Hagen defined goals as 'very general and global statements which are supposed to serve as an overall frame of reference'. ${ }^{17}$ (p 200) Although the definition of a goal was relatively abstract, behavioural objectives were very specifically defined. They are precise statements that begin with an action verb and which characterise observable behaviour pertaining to intended direct outcomes that are both realistic and at an appropriate level of generality. In 1977, when Thorndike and Hagen wrote their text, the word 'competency' did not even appear in their index. ${ }^{17}$ Similarly, in their 1985 book on assessing clinical competence, Neufeld and Norman $^{18}$ did not give a succinct definition of what a competency was, but described in considerable detail how competencies could be derived.

Thus, whereas goals and, especially, objectives have been quite well defined in terms of form and structure in the literature, what constitutes a competency seems to depend somewhat on the eye of the beholder. Indeed, many competencies that have been developed tend to consist of a blend of what have been termed elsewhere as 'goals' and 'objectives'. This may or may not be a problem. Some goals and objectives may be presented in such a way that we would argue that they meet the criteria for competencies. What distinguishes a competency from a goal or objective is that it focuses on the end-product of the instructional process, rather than on the instructional process itself, or that it embraces the larger picture rather than the content of a single course. Ultimately, it is not just words and phrasing that determine whether a statement refers to a goal, an objective or a competency, but what is done with it. If a statement or a list of statements in a course syllabus serve no purpose other than to describe the needs of the course, they do not refer to competencies. Competencies are used to set performance standards that must be met.

An even more confusing issue concerns the distinction between outcomes and competencies. The 12 outcomes comprising the DOM (see Appendix S2 [supplementary material]) have much in common with competencies. An outcome model is a means of 
'identifying, defining and communicating the skills and qualities we want doctors to have'. ${ }^{10}$ A competency model starts with a focus on patient care outcomes and takes the additional step of determining which outcomes doctors need to have. The distinction between what we want and what we need in our doctors may be subtle, but it is important.

\section{Proposed criteria for defining a competency}

Harden et al. ${ }^{10}$ set out 7 criteria for the specification of outcomes, which state that they:

1 reflect the vision and mission of the institution as perceived by the various stakeholders; the institution, the commissioners of the education and the public;

2 are clear and unambiguous;

3 are specific and address defined areas of competence;

4 are manageable in terms of the number of outcomes;

5 are defined at an appropriate level of generality;

6 assist with development of 'enabling' outcomes, and

7 indicate the relationship between different outcomes.

Although we might quibble with some of these 7 criteria, for the most part they would also apply to the creation of competencies. We propose, however, that a competency (at least in an instructional context) should have the following additional 5 characteristics.

1 It should focus on the performance of the end-product or goal-state of instruction. In medical education, this could be a practising doctor or, perhaps, a trainee who possesses the clinical skills and ability necessary for assuming the patient care responsibilities of residency. There may be some situations in which an even more near-term end-product is an appropriate focal point, such as readiness for progression to Year 2 for medical students on Year 1 courses.

2 It should reflect expectations that are an application of what is learned in the immediate instructional programme. Thus, a competency for a doctor would reflect his or her ability to use information and skills in patient care, not to recall information contained in a specific course. Clearly, recalling information is a necessary step that enables a doctor to apply material learned to patient care, but it is in the context of patient care that the information must be used or applied to reflect competence.
3 It should be expressible in terms of measurable behaviour. The global statements of competencies developed by the ACGME/ABMS, CanMEDS 2005, IIME and DOM (see Appendices S1 and S2 [supplementary material]) are statements of the expected capabilities of a learner at a relatively high level of abstraction and generality (which is the only way that $6,7,11$ or 12 statements could possibly cover all the requirements involved in being a doctor). Specifying the behaviours expected from competence is essential to being able to actually measure the attainment of the competency. Behaviours used to assess competencies are distinguishable from behavioural objectives because they can be held to standards that define the subject as 'competent/not competent,' whereas objectives are derivatives of instruction, which often guide student study, curriculum development and programme evaluation. Whereas objectives are tied to specific instruction and are building blocks of competencies and outcomes, they are generally insufficiently focused to serve the assessment needs for which competencies are designed.

4 It should use a standard for judging competence that is not dependent upon the performance of other learners. Thus, competence and the measurable behaviours associated with being competent represent a level of achievement that all learners can attain. This type of performance would be best measured by what has sometimes been termed 'criterion-related assessment'. It also brings in the whole complex domain of standard setting.

5 It should inform learners, as well as other stakeholders, about what is expected of them. Thus, the more competencies and how they are measured are described in clear and non-technical terms, the more they will fulfil this requirement. However, the communication of expectations to non-medical audiences is not a primary goal of competencies, but it is desirable when possible.

Although this criterion overlaps to some extent with the second criterion for an outcome defined by Harden et al., ${ }^{10}$ it has a more specific purpose. To be of most benefit, competencies and, especially, how they are measured should be presented in such a way that learners know what they are expected to do (.i.e. they should be given guidelines for how they should be able to learn what they are expected to do) and then provided with instructions for how they are to demonstrate what they are expected to do. This enables learners to claim at least some degree of control over their own learning and assessment. 


\section{Theoretical basis for criteria}

The DOM was derived from 3 essential elements or dimensions of the competent and reflective medical practitioner: what the doctor is able to do; how the doctor approaches his or her practice, and the doctor as a professional. The relationships among these 3 elements are conceptualised as concentric circles, with the element pertaining to what the doctor is able to do at the centre or core. These are the technical skills that the doctor possesses, such as clinical skills (medical informatics, patient management, patient investigation, etc.). The next concentric circle refers to how the doctor approaches his or her practice (attitudes, ethical understanding and legal responsibilities, decision-making skills, clinical reasoning, judgement, etc.). This builds on what the doctor is able to do at the core so that as we progressively move to the outside of the circle, we continually build on the inner circles. The outer concentric circle builds on the 2 inner circles to yield the doctor as a professional (role of the doctor in the health care system; personal development). Each of the 3 dimensions has different outcomes attached to it (amounting to 12 outcomes in all). Each outcome corresponds to 1 of the 3 dimensions, from the core dimension (what the doctor is able to do), through the second dimension (how the doctor approaches his or her practice) to the outer dimension (the doctor as a professional). (See Appendix S2 [supplementary material]). In addition to linking the outcomes to the 3 dimensions of the work of a doctor, Harden et al. ${ }^{10}$ linked each outcome to 1 of 5 types of intelligence based upon Gardner's theory of multiple intelligences, ${ }^{11}$ namely, technical, intellectual, emotional, analytical and creative, and personal intelligences. (See Appendix S2 [supplementary material]).

The derivation of competencies has its roots in both the conditions that motivate it and theoretical positions that can be considered to underlie its effectiveness. Whereas the derivation of outcomes is generally motivated by a desire to link expectations for learners to the skills and abilities of the practising doctor, the movement towards competencies is based upon the additional concern that medical graduates who go on to practise may lack some of the basic doctoring skills. Competencies are generally considered to be part of a system that can ensure that all graduates and practising doctors have the minimum doctoring skills needed for successful practice.

One of the theories underpinning the competency movement is that of behaviourism, also called 'behaviour modification'. ${ }^{19}$ At its core are concepts that have emerged from what is called 'operant conditioning'. Perhaps the most relevant aspect of operant conditioning for competency-based education is that if we reward (positively reinforce) behaviour we wish to recur, that behaviour will increase in frequency in the future. Similarly, if we administer a punishment (negative reinforcement) when a behaviour occurs, that behaviour is less likely to occur in the future. To be maximally effective the reinforcement should come as quickly as possible after the behaviour occurs. Research has shown positive reinforcement to have the greater influence on producing desired behaviour, and competency-based education tends to emphasise positive reinforcement. In the case of competencies, the positive reinforcement (reward) is represented by the acknowledgement that the student has achieved competence. Thus, measuring and quickly acknowledging whether or not achievement of competence has occurred would be consistent with the behaviourist model. Snelbecker ${ }^{20}$ includes programmed instruction among the outgrowths of behavioural theory. Features of programmed instruction that are relevant for competency-based education involve the arrangement of educational materials in small, relatively easyto-take steps and in the best possible sequence for students. Other relevant features include allowing students to work at their own pace and allowing them to take as much time as they need to achieve educational objectives (competencies). ${ }^{20}$ (p 393) Behaviour modification relies on observable behaviours or objectively measurable characteristics, with comparatively minimal concern with the internal experiences of the student. It also requires that 'one provide explicit descriptions of one's objectives and procedures. This involves specifying educational objectives in some objectively measurable form, identifying the entering characteristics of the individual students, describing the instructional procedures which are to be implemented, and outlining what evaluative procedures are to be used in assessing students' progress and in planning modifications to the instructional procedures. ${ }^{20}$ (p 400) Programmed instruction also uses modelling as a method to develop skills by 'having the student imitate the teacher who serves as a model, or by showing the student at least partly completed products of appropriate behaviour which he can copy' $^{20}$ (p 400)

Although behaviour modification has been criticised for developing a dependency on external rewards, there is no question that it can change behaviour. In the 5 criteria we propose, the first 2 are directed at outcomes and derive from the basic theory that 
Harden et al. ${ }^{10}$ proposed. The last 3 are consistent with behaviour theory and focus on providing clear specifications of the competency criteria as well as the means by which performance will be judged. Implicit in any competency-based programme is that the goal is competence and the passing of time is not a factor in determining that competence. This clearly is consistent with behaviour theory.

\section{Applications of the criteria}

So how might a competency fail to meet the 5 characteristics? Suppose we take the following competency:

'Medical knowledge': demonstrate knowledge of the Kreb's cycle through performing better than the lowest $5 \%$ of students on the course examination.

Although this is a quite extreme example, it illustrates the violation of several of the criteria. It has no relationship to an end-product, even for a student who successfully passes the course. The competency is narrowly focused on the specific content of a course, making no reference beyond the specific information that is considered important to the course. This competency evaluates performance solely on the basis of the performance of other students, which makes it difficult for students and stakeholders to evaluate if this is important or not. Thus, this example violates 4 of the 5 criteria for a competency.

This example is a clear-cut and extreme case of failure to meet criteria for a competency. Other clear-cut examples that would not satisfy the criteria would be competency-type statements or assessments derived from presenters who focus on their current research or from clinicians who focus on their specialty while continually pointing to the shortcomings of other specialties, measurements such as tests that assess minutia versus end-state practitioner-needed knowledge, etc. The more typical example of a competency that is not a competency may not be evident from just inspection. The merit of a competency is defined as much by the process by which the competency is determined as the exact wording with which it is presented. Thus, a statement that is currently called a goal or objective might also be a competency if it were derived from an analysis of what a doctor needs to be a competent practitioner and if it met the other 4 criteria we set out. In the competency framework we propose, competencies are not uniquely different from what have been called goals, objectives and outcomes; they just are more specifically targeted to achieve the goal of ensuring the competence of the learner based upon clear criteria grounded in the skill-set needed by a practitioner.

\section{Can a single set of competencies serve the world?}

A final point concerns whether a single set of competencies could serve a universal purpose worldwide. The IIME competencies were intended to serve such a purpose. However, even countries with as many similarities between them as the USA and Canada in terms of background and sophistication of medical systems have separate sets of competencies that govern the practice of medicine. Taking the comparison further, the CanMEDS 2005 and DOM are probably even more divergent than the CanMEDS 2005 and ACGME/ABMS competencies; yet both derive from a centralised health care system in countries within the British Commonwealth. Global competencies such as those defined by the IIME, CanMEDs 2005, DOM and the ACGME/ABMS are as much political statements about what is valued as they are statements about what doctors will be held accountable for. Whether the divergences in competencies represent real differences or semantics cannot be established until we dig to the level of the behaviour measured. It is at that level that the process needs to be tailored to the individual context. Thus, although it may be possible to achieve agreement on the wording of global competencies, it is at the point where the competencies are behaviourally measured that McGaghie et al. ${ }^{16}$ are probably correct in their assertion that the definition of competence is inextricably bound to local political, social and economic circumstances, to health needs, to the availability of resources, and to the structure of the health care system. As such, for the foreseeable future, it is doubtful that it will be possible to achieve universal agreement on global competencies, let alone on how the competencies will actually be measured.

\section{DISCUSSION}

Competency-based medical education is likely to be here for the foreseeable future. The lack of defining characteristics for what constitutes a competency has been a source of confusion for many. The diversity of form and structure embodied in current statements of competencies are the result of this void. In our definition, goals and objectives are statements that focus on the instructional process and programme, whereas competencies focus on the goal-state or endproduct. Competencies are the subset of outcomes 
that practising doctors need to function at the desired level. Although outcomes are more broadly defined as being desirable of the practising doctor and reflect Gardner's theory of multiple intelligences, ${ }^{11}$ competencies are based upon behaviour theory and its focus on producing specific desired behaviours. If an instructional programme is specifically built around producing end-product outcomes, then goals and objectives may also meet the criteria for outcomes and competencies. There is nothing magical about the wording of competencies that sets them apart; it is the process by which they are derived and their constant focus on the skills, abilities and other qualities needed in the practising doctor that define them. Whether the 5 criteria we propose prove to be useful in steering the juggernaut of competency-based education remains to be seen. Whether or not these, or some variation of them, become the ultimate defining criteria for what constitutes a competency, clear definitions are an essential step in clearing the confusion that reigns.

Contributors: all authors made substantial contributions to the conception and design of this paper and to its critical revision for important intellectual content. All authors approved the final manuscript.

Acknowledgements: this article is based upon a presentation given by the first author as the 2005 Jack L Maatsch Visiting Scholar in Medical Education at Michigan State University. The authors wish to thank the selection committee for providing the impetus for this article.

Funding: none.

Conflicts of interest: none.

Ethical approval: not applicable.

\section{REFERENCES}

1 Spady WG. Competency-based education; a bandwagon in search of a definition. Educ Res 1977;6 (1):9-14.

2 Carraccio C, Wolfsthal SD, Englander R, Ferentz K, Martin C. Shifting paradigms: from Flexner to competencies. Acad Med 2002;77 (5):361-7.

3 Merenstein JH, Schulte JJ. STFM Task Force on residency curriculum of the future. A residency curriculum for the future. Fam Med 1990;22:467-73.

4 Frank JR, ed. The CanMEDS 2005 Physician Competency Framework. Better Standards. Better Physicians. Better Care. Ottawa: Royal College of Physicians and Surgeons of Canada 2005.

5 Medical School Objectives Project. Learning objectives for medical student education - guidelines for medical schools. Report 1 of the Medical School Objectives Project. Acad Med 1999;74 (1):13-8.

6 Horowitz SD, Miller SH, Miles PV. Board certification and physician quality. Med Educ 2004;38 (1):1364-5.
7 Albanese M. Developing effective, efficient and practical methods of assessing the professional skills of physicians in practice. Med Educ 2004;38 (1):4-5.

8 Leach DC. A model for GME: shifting from process to outcomes. A progress report from the Accreditation Council for Graduate Medical Education. Med Educ 2004;38 (1):12-4.

9 Harden RM, Crosby JR, Davis MH. AMEE Guide No. 14. Outcome-based education, part 1. An introduction to outcome-based education. Med Teach 1999;21 (1):7-14.

10 Harden RM, Crosby JR, Davis MH, Friedman M. AMEE Guide No. 14. Outcome-based education, part 5. From competency to meta-competency: a model for the specification of learning outcomes. Med Teach 1999;21 (6):546-52.

11 Gardner H. Frames of Mind. New York: Basic Books 1983.

12 Whitcomb M. Competency-based graduate medical education? Of course! But how should competency be assessed? Acad Med 2002;77 (5):359-60.

13 Council on Linkages between Academia and Public Health Practice. The Competencies Project. http:/ / www.trainingfinder.org/competencies/background. htm. [Accessed 17 October 2007.]

14 Albanese M. The Rise of Competencies. Presentation on Receipt of the Jack L Maatsch Visiting Scholar in Medical Education Award. Lansing, MI: Michigan State University 2005.

15 Neufeld VR. Historical perspectives on clinical competence. In: Neufeld VR, Norman GR, eds. Assessing Clinical Competence. Springer Series on Medical Education, Vol 7. New York: Springer Publishing 1985;3-14.

16 McGaghie WC, Miller GE, Sajid AW, Telder TV. Competency-based Curriculum Development in Medical Education: an Introduction. Geneva: World Health Organization 1978.

17 Thorndike RL, Hagen EP. Measurement and Evaluation in Psychology and Education, 4th edn. New York: John Wiley \& Sons 1977;200.

18 Neufeld VR, Norman GR. Assessing Clinical Competence. Springer Series on Medical Education, Vol 7. New York: Springer Publishing Co. 1985.

19 Ferster CB, Perott MC. Behavior Principles. New York: Appleton-Century-Crofts Publishers 1968.

20 Snelbecker GE. Learning Theory, Instructional Theory, and Psychoeducational Design. New York: McGraw-Hill, Inc. 1974.

\section{SUPPLEMENTARY MATERIAL}

The following supplementary material is available for this article:

Appendix S1. American Board of Medical Specialties/Accreditation Council for Graduate Medical Education, CanMEDS 2005 and Institute for International Medical Education competencies aligned by common elements. 
Appendix S2. American Board of Medical Specialties/Accreditation Council for Graduate Medical Education and Dundee Outcome Model competencies aligned by common elements.

Appendix S3. Analysis American Board of Medical Specialties/Accreditation Council for Graduate Medical Education competencies evaluated against the 5 criteria to show their viability.

This material is available as part of the online article from: http://www.blackwell-synergy.com/doi/abs/10.1111/ j.1365.2923.2007.02996.x
(This link will take you to the article abstract.)

Please note: Blackwell Publishing is not responsible for the content or functionality of any supplementary materials supplied by the authors. Any queries (other than for missing material) should be directed to the corresponding author for the article.

Received 21 December 2006; editorial comments to authors 11 June 2007, 12 October 2007; accepted for publication 26 October 2007 